\title{
Effect of Diagnostic Testing on Students' Achievement in Secondary School Quantitative Economics
}

\author{
Nkechi Patricia-Mary Esomonu ${ }^{1} \&$ Lydia Ijeoma Eleje ${ }^{1, *}$ \\ ${ }^{1}$ Faculty of Education, NnamdiAzikiwe University, Awka Anambra State, Nigeria \\ *Correspondence: Department of Educational Foundations, Faculty of Education, Nnamdi Azikiwe University, \\ Awka, PMB 5025, Awka, Nigeria. Tel: 234-803-275-6383. E-mail: ijeomaexcite@gmail.com
}

Received: February 9, 2020

Accepted: April 17, $2020 \quad$ Online Published: June 20, 2020

doi:10.5430/wje.v10n3p178

URL: https://doi.org/10.5430/wje.v10n3p178

\begin{abstract}
This study aimed at investigating the effect of diagnostic testing on students' academic achievement in secondary school quantitative economics. In conducting the study, 3 research questions and 3 stated hypotheses were answered. The study is quasi-experimental employing $2 \times 4$ factorial pretest-posttest design. The sample consisted of 210 Senior Secondary 3 (SS3) economics students in the four co-educational schools purposely selected from Nnewi Education Zone of Anambra State in Nigeria. They were allocated to 3 experimental groups and 1 control group. Students' responses to two instruments titled Diagnostic Quantitative Economics Skill Test (DQEST) and Test of Achievement in Quantitative Economics (TAQE) constituted relevant data for the study. Instruments for data analysis were t-test and ANCOVA. Results of the analysis indicate a significant effect of treatment on students' achievement in favor of DQEST with feedback and remediation group only $(\mathrm{F}(3,209)=22.3114, \mathrm{p}>0.05)$. Gender made no significant difference on students' achievement in TAQE. Thus, diagnostic tests are effective when used with feedback and remediation. The use of DQEST with feedback and remediation in teaching and learning of quantitative economics is therefore recommended.
\end{abstract}

Keywords: diagnostic test, diagnostic testing, feedback, remediation, achievement, quantitative economics

\section{Introduction}

In any educational process or development, evaluation plays a major role. Evaluation enables the teacher to determine the extent to which educational objectives have been achieved. Habitually used evaluation process which provides indices of students' achievement is testing. The student's endeavors in his or her educational involvement is verified through testing. It also amalgamates subjects, encourages self-assurance and intellectual skills and thus, motivates academic progress. Dixon (2009) noted that testing releases the parent unnecessary and impractical burden by not necessitating them to play the role of expert in evaluation. Educational legislators, teachers, and researchers are ever more concerned in testing as it truly reflects students' achievement (Ozan \& Kincal, 2018).

Formative testing, summative testing as well as diagnostic testing are commonly used testing processes to measure how much of the assigned materials students are mastering. It also indicates how well students are learning the materials, and learning problems that constrains students' meeting the stated goals and objectives. In formative testing, students' learning are being evaluated multiple times during the unit of instruction or educational program with the aim of providing teachers feedback of students' mastery of what is taught. The feedback provided can aid the teachers to modify their teaching methods, materials, and educational sustenance. Summative testing, on the other hand, evaluates student's learning in order to produce feedback regarding students' educational advancement and achievement. That is for the benefits of -students, teachers, parents, and the society. Therefore, such feedback comes typically at the conclusion of teaching and learning, term, educational program, or session (Schaffer, 2013; Shavelson et al., 2008).

Diagnostic testing is the process adopted to locate and identify students' areas of learning difficulties/weaknesses in a subject or skill and the cause. It implies a detailed study of learning weaknesses (Ketterlin-Geller \& Yavanoff, 2009). It involves assessing components of underlying skills out of the context of the curriculum. Diagnostic testing tends to expand the student's knowledge and achievement. Nevertheless, diagnostic testing gazes rearward instead of forwards. Its purpose is to assess students' prior knowledge in addition to the type of learning problems the student may 
encounter. Such problems can reduce students' commitment in new learning if not diagnosed (Highland Council of Education, Culture and Sport Services, 2010). It is often administered prior to teaching and learning or when a problem arises.

Diagnostic testing is accomplished when a student continues to experience learning difficulties despite all efforts to improve, then there is a need to embark on a detailed diagnosis of the student's learning problem. Performing diagnostic testing to the student enables the teacher to determine the nature and the cause of a student's learning difficulty, with the main purpose of correcting and remedying the difficulty involved. It helps the teacher to diagnose and identify the specific problems each of the students has in studying a subject. That is, to locate the particular area where the difficulty lies or the particular concept where the student commits errors. Hence, the main aim of diagnostic testing is to find out a student's weak learning point and not how much the student scores (Ofem, Idika, \& Ovat, 2017).

In diagnostic testing, application of diagnostic test, feedback and remediation needs to be implemented in order to produce desired learning outcomes and to facilitate goal attainment. Diagnostic test assesses specific learning skills of the syllabus; main skills of rudimentary or absolute kind, the syllabus is required to develop. Such tests are used to give objective, standardized data on pupil skill levels and to identify the students' exact weak learning point in the topic/skill taught. The development process of a diagnostic test requires that specific skills essential for positive achievement in the subject are compulsorily covered. Consequently a diagnostic test generally comprises subtests. Separately each subtest assesses one specific component or skills. In developing diagnostic tests, Ofem et al, noted that the items will be in a form that students are given the chance of making mistakes which will reveal their weaknesses.

Therefore, the teacher or evaluator in performing diagnostic testing has the specific aim to search and retrieve information or to analyze learners' answers to the diagnostic test so as to pinpoint specific kinds of mistakes each student makes. This analysis may be interpreted in terms of each student, a group of students, each concept/competency and for each question and then reported as feedback to the students or any appropriate authority ("Evaluation and enrichment," n.d). For feedback to be effective, there must be a learning situation to which feedback is regarded to. It does not operate in vacuum. Feedback occurs second after a student has attended to a certain task; when data is generated regarding achievement of students in a task ("Evaluation and enrichment," n.d). Feedback is as a result of responding to a diagnostic test. Analysis of students' responses to a diagnostic test provides feedback which is to direct the teacher in preparation of materials for remediation of different learning difficulties faced by the students. While diagnoses is the application of diagnostic tests to investigate student's learning difficulties and the reasons for this, its follow up leads to remediation. That is, actions that may help to circumvent reoccurring of students' learning difficulties. The teacher undertakes this kind of probe or diagnoses into the performance of students to ensure the quality of learning and to know what specific action should be taken to obtain the desired results. This specific action to be taken is in the form of corrective measures, termed as remediation.

Diagnostic testing according to Casmir (2014) is mostly pertinent in subjects that attainment of specific skills or information is a requirement for the learning of advanced theories. As such it is important in economics as a subject where quantitative economics skill according to the Chief examiners' report is required for a candidates' improved performance in economics examinations (WAEC 2012, 2014, 2017 \& 2018). Nevertheless, a major question that needs to be verified is whether diagnostic testing that provides detailed diagnosis of students' strengths and weaknesses affects students' achievement positively? Very little is known about the effect of such testing on students' achievement. A search on the literature revealed that there are sparse studies conducted on the effect of diagnostic testing on students' achievement (Alderson, 2005; Jang, 2009 \& Richards, 2008).

The available study was that of (Betts, Hahn, \& Zau, 2015; Ofem et al., 2017). Betts et al carried out a study to find out if diagnostic mathematics testing improves student learning. The authors of Betts et al study examined how both the voluntary use of mathematics diagnostics test (MDT) by separate teachers and compulsory testing by the San Diego Unified School District (SDUSD) California affect the mathematics achievement of students in California USA. The authors of Betts et al study covered a period of 6 years with 135,000 students enrolled in preschool through grade 12 . The authors found that mandatory use of MDT boosts students' scores from $50^{\text {th }}$ percentile to somewhere between $54.6^{\text {th }}$ and $57^{\text {th }}$ percentile on average per year after mandated testing by the district. They also found that if a student is given MDT two years in a row, the achievement of the student a year after the first test was strengthened in the second year. They also observed that if a student is given MDT in one year but not the next, the benefits of MDT decay over time.

Also, Ofem et al examined the influence of diagnostic and feedback evaluation methods in improving among Secondary School students' achievement in mathematics. A total of 119 students from 3 secondary schools were used for Ofem et al study. Two schools constituted the experimental groups while one school was used as control. The 
researcher designed the Mathematics Achievement Test (MAT) for data collection. The result of the data analysis revealed that diagnostic and feedback evaluation methods enhance achievement in Mathematics. In their study, Ofem et al did not utilize a developed and validated diagnostic test in their diagnostic assessment, rather certain questions were posed to the students for the researchers to gather data on the extent of intellectual accomplishment and not for identifying students' weak learning points.

To the best of our knowledge, until now only these two studies by Betts, et al, (2015) and Ofem et al, (2017) on the effect of diagnostic testing on academic achievement have been researched on. Thus, further research towards finding how the use of diagnostic tests affects learning outcomes were requested by these researchers (Alderson, 2005; Eleje et.al., 2015; Esomonu \& Eleje, 2017; Jang, 2009; Richards, 2008). Based on this, one expects that this study that investigates the effect of diagnostic testing on students' achievement in secondary school quantitative economics was one of the responses to the call and definitely will support the existing literature. In this study, the effect of diagnostic testing (application of diagnostic test, feedback and remediation) on students' academic achievement in secondary school quantitative economics is investigated. To address the above problem, the following research questions and hypotheses were analyzed.

\subsection{Research Questions}

1) What are the gain in mean achievement test scores in quantitative economics for students who received DQEST with feedback and remediation (group I), DQEST with feedback (group II), DQEST only (group III), and non DQEST (control group)?

2) What are the gain in mean achievement test scores in quantitative economics for males and females student?

3) What are the gain in mean achievement test scores in quantitative economics of males and females student for experimental groups I, II, III, and control?

\subsection{Hypotheses}

HO1: There is no significant difference between the mean achievement test scores in quantitative economics of students exposed to treatments.

HO2: There is no significant difference between the mean achievement test scores in quantitative economics of male and female students in experimental group 1.

HO3: There is no significant difference between the mean achievement test scores in quantitative economics of males and females student in experimental group 2.

HO4: There is no significant difference between the mean achievement test scores in quantitative economics of males and females student in experimental group 3.

\section{Method}

The study plan is quasi experimental using $2 \times 4$ factorial pretest-posttest design. The study population consisted of 755 Senior Secondary 3 (SS3) students offering economics in the 37 public coeducational secondary schools from the four Local Government Areas (LGAs) of Nnewi education zone, Anambra State in Nigeria. The study sample consisted of 210 SS3 students offering economics -males 86 and females 124- from 4 coeducational secondary schools in the zone. These four schools which have finished the teaching and learning of diagnostic quantitative economics skill content and are not in the same (LGAs) were selected using purposive sampling technique while simple random sampling technique was used to allocate the four schools to the four treatment conditions (group 1 was given diagnostic test with feedback and remediation, group 2 was given diagnostic test with feedback, group 3 was given diagnostic test only and the control group -group 4- was not given neither diagnostic test, feedback nor remediation). All the SS3 students offering economics from the four schools were used in the study.

Two instruments titled Diagnostic Quantitative Economics Skill Test (DQEST) and Test of Achievement in Quantitative Economics (TAQE) were used for data collection. DQEST and TAQE were existing instruments developed by Esomonu and Eleje (2017), and Eleje and Esomonu (2018) respectively from the 9 sub-skills of secondary school quantitative economics contents on which the experiment was based. In this study, DQEST which consisted of 50 multiple choice questions was shared into four sections. Section 1 contains two sub-skills of 12 items, section 2 contains two sub-skills of 11 items, section 3 has two sub-skills of 15 items and section 4 consists of three sub-skills of 12 items. On the other hand, TAQE which is of 20 multiple choice questions was used as the pretest and posttest to the study. It was used to gather important data for the investigation. Collected data were analyzed with $t-$ 
test and ANCOVA and the rejection or acceptance of the stated hypotheses were at 0.05 level of significance. Where a null hypothesis was not accepted, Bonferroni's Post Hoc analysis was conducted to determine where the significance lies, that is the treatment situation that triggered the rejection.

\section{Result}

Data collected based on the stated research questions were analyzed and the resulting outcomes presented.

Research question 1: What are the gain in mean achievement test scores in quantitative economics for students who received DQEST with feedback and remediation (group I), DQEST with feedback (group II), DQEST only (group III), and non DQEST (control group)?

The Table 1 presents the gains in mean scores in TAQE of students in experimental groups I, II, III, and control.

Table 1. The Gains in Mean Scores in TAQE for the Four Treatment Groups

\begin{tabular}{lllll}
\hline Groups & N & $\begin{array}{l}\text { Pretest } \\
\text { Means }\end{array}$ & $\begin{array}{l}\text { Posttest } \\
\text { Means }\end{array}$ & $\begin{array}{l}\text { Gains in Means Scores } \\
\text { (Difference in Means) }\end{array}$ \\
\hline DQEST with Feedback and Remediation (Group I) & 60 & 5.88 & 8.55 & 2.67 \\
DQEST with Feedback (Group II) & 62 & 5.08 & 5.98 & 0.90 \\
DQEST Only (Group III) & 43 & 5.14 & 5.67 & 0.54 \\
Control group & 45 & 5.22 & 5.33 & 0.11 \\
\hline
\end{tabular}

In Table 1, posttest mean for the four treatment groups is higher than their pretest mean. But the gain in mean scores for students who received DQEST with feedback and remediation (group I) improved higher than those in experimental groups II, III, and control.

Research question 2: What are the gain in mean achievement test scores in quantitative economics of males and females student for experimental groups I, II, III, and control?

The Table 2 presents the gains in mean scores in TAQE of males and females student in experimental groups I, II, III, and control.

Table 2. Gain in Mean Achievement Scores of Males and Females Student for the Four Experimental Groups

\begin{tabular}{lllccc}
\hline Groups & Gender & N & Pretest & Posttest & $\begin{array}{c}\text { Gain in } \\
\text { Mean Score }\end{array}$ \\
\hline DQEST with Feedback and Remediation (Group I) & & & & & \\
& Males & 17 & 6.29 & 8.59 & 2.30 \\
& Females & 43 & 5.72 & 8.53 & 2.81 \\
& & & & & \\
& & & & \\
& Males & 24 & 5.25 & 5.75 & 0.50 \\
DQEST with Feedback (Group II) & Females & 38 & 4.97 & 6.13 & 1.16 \\
DQEST Only (Group III) & Males & 21 & 4.81 & 5.48 & 0.67 \\
& Females & 22 & 5.45 & 5.86 & 0.41 \\
Control Group (Non DQEST) & Males & 24 & 5.46 & 5.04 & -0.42 \\
& Females & 21 & 4.95 & 5.67 & 0.72 \\
\hline
\end{tabular}

As observed in Table 2, the female students in DQEST with feedback and remediation, DQEST with feedback and non DQEST groups consistently had higher gains in mean than male students except for the DQEST only group. The male students in control group had loss in gain in mean.

The data collected based on the stated research hypotheses were analyzed and the resulting outcomes presented. The stated hypotheses were tested at 0.5 level of significance using Analyses of Covariance (ANCOVA) and t-test statistics.

Hypothesis 1 aimed to determine how different treatments (DQEST with feedback and remediation, DQEST with feedback, DQEST only and non DQEST) affect quantitative economics achievement of students. The summary result of ANCOVA is seen in Table 3. 
Table 3. Summary of ANCOVA Result for Comparing Posttest Mean Scores in TAQE Based on Treatment

\begin{tabular}{lrrrrr}
\hline \multicolumn{1}{c}{ Type III Sum of } & & & & \\
Source & Squares & df & Mean Square & \multicolumn{1}{c}{ F } & \multicolumn{1}{c}{ Sig. } \\
\hline Corrected Model & $419.790^{\mathrm{a}}$ & 4 & 104.948 & 27.772 & .000 \\
Intercept & 575.167 & 1 & 575.167 & 152.206 & .000 \\
PRETEST & 60.609 & 1 & 60.609 & 16.039 & .000 \\
Treatment & 303.250 & 3 & 101.083 & 26.750 & .000 \\
Error & 774.667 & 205 & 3.779 & & \\
Total & 10106.000 & 210 & & & \\
Corrected Total & 1194.457 & 209 & & & \\
\hline R Squared $=351$ (Adjusted R Squared $=339)$ & & & &
\end{tabular}

In Table 3, the summary of ANCOVA result shows that the dissimilarity between the mean achievement test scores in quantitative economics of students exposed to DQEST with feedback and remediation, DQEST with feedback, DQEST only and non DQEST was significant $(F(3,209)=26.750$, p-value $<0.05)$. The null hypothesis was therefore rejected. The result of the analysis also indicate a significant main effects of treatments on students' achievement in TAQE. To determine where the difference lies Bonferroni's Post Hoc analysis was conducted. The result is portrayed in Table 4.

Table 4. Pair-wise Comparison (Post hoc) of the Treatment Main Effects

\begin{tabular}{lllll}
\hline GROUPS (I) & GROUPS (J) & Mean Difference (I-J) & Std. Error & Sig.b \\
\hline DQEST with Feedback and & & & & \\
Remediation (Group I) & Group II & $2.364^{*}$ & 0.383 & 0.000 \\
& Group III & $2.640^{*}$ & 0.413 & 0.000 \\
& Control group & $2.977^{*}$ & 0.408 & 0.000 \\
DQEST with Feedback (Group II) & Group III & 0.277 & 0.391 & 1.000 \\
& Control group & 0.613 & 0.387 & 0.685 \\
DQEST Only (Group III) & Control group & 0.337 & 0.416 & 1.000 \\
\hline
\end{tabular}

As Table 4 shows, the treatment situation that triggered the rejection of hypothesis 1 was DQEST with feedback and remediation. It means that the treatment condition that was significantly effective in improving students' achievement in quantitative economics was DQEST with feedback and remediation. Table 4 also shows a non-significant difference between the posttest mean scores in TAQE of students provided with DQEST with feedback, DQEST only, and non-DQEST (control group).

The focus of hypotheses two, three and four was to determine whether a significant dissimilarities exist among male and female students in increasing their achievement in quantitative economics. To achieve this aim, the male and female students' mean achievement posttest scores in quantitative economics were compared through t-test of independent sample.

Table 5. Mean and Standard Deviation of Males and Females Student for Experimental Groups in the Posttest

\begin{tabular}{llcccc}
\hline $\begin{array}{l}\text { Experimental } \\
\text { Groups }\end{array}$ & Gender & N & Mean & Std. Deviation & Std. Error Mean \\
\hline Group 1 & Female & 43 & 8.53 & 2.074 & .316 \\
& Male & 17 & 8.59 & 1.770 & .429 \\
Group 2 & Female & 38 & 6.13 & 2.362 & .383 \\
& Male & 24 & 5.75 & 2.192 & .447 \\
Group 3 & Female & 22 & 5.86 & 2.145 & .457 \\
& Male & 21 & 5.48 & 1.250 & .273 \\
Group 4 & Female & 21 & 5.67 & 1.713 & .374 \\
& Male & 24 & 5.04 & 2.010 & .410 \\
\hline
\end{tabular}


In Table 5, is shown posttest mean achievement scores of males and females student for the experimental groups. Female students mean scores in experimental groups 2, 3 and 4 were slightly greater than male students mean scores while group 1 is the opposite. The t-test of Independent Sample conducted was to check how significant or not the dissimilarities are.

The Table 6 presents the t-test results for the dissimilarity among posttest mean achievement scores in quantitative economics for males and females student in experimental groups two, three and four.

Table 6. t-Test of Independent Samples for Comparing Males and Females Student of Experimental Groups 1-4 on the Posttest

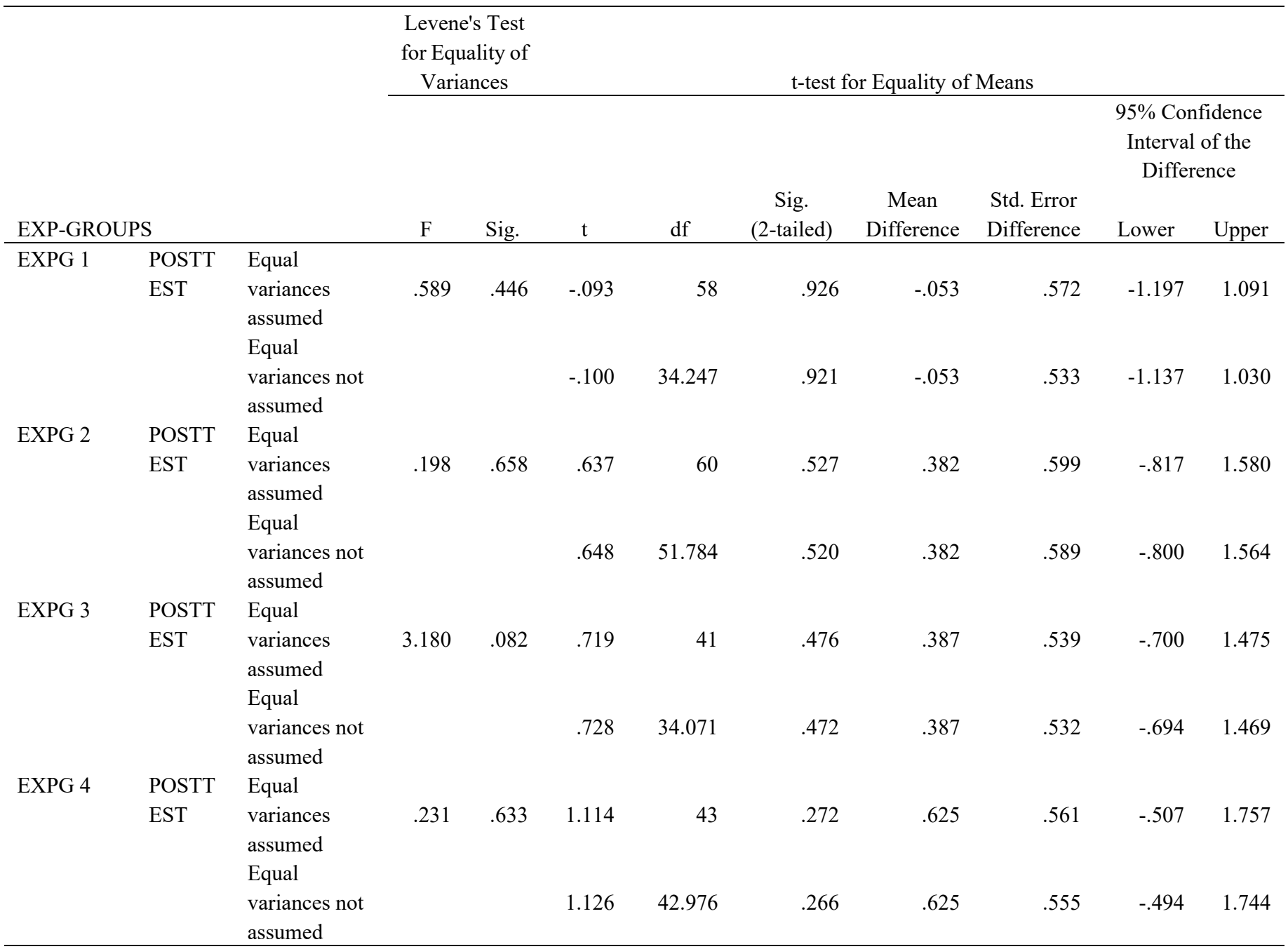

As seen in Table 6, there was non-significant dissimilarity between males and females student achievement in quantitative economics since the $p$ values were greater than $.05(p=.926, .527, .476, .272)$. Thus, both males and females student in group 1 benefitted similarly from DQEST with feedback and remediation treatment, both male and female students in treatment group 2 benefitted alike from DQEST with feedback treatment, both males and females student in treatment group 3 benefitted in the same way from DQEST only treatment, and both males and females student in group 4 (control group) benefitted equally from non-DQEST treatment.

\section{Discussion}

The study result revealed that diagnostic testing improved students' achievement. This finding provides empirical support to earlier findings by Betts et al, (2015), Ofem et al, (2017) and Rusrus (2007) that recorded an increase in learners' achievement when diagnostic tests go together with feedback and a corrective measure-remediation. Though the groups' mean achievement scores that were similar at pretest level increased at posttest level, the 
students provided with diagnostic test with feedback and remediation had higher achievement in TAQE, followed by those that received diagnostic test with feedback, diagnostic test only and non-diagnostic test. Group 4 (control group) that was not given either diagnostic test, feedback or remediation recorded the least achievement in TAQE.

The efficacy of the treatments was as well established through analysis of covariance to check for significant outcomes which the diverse treatments (DQEST with feedback and remediation, DQEST with feedback, DQEST only and non DQEST) had on students' achievement in quantitative economics. The result of the ANCOVA showed that the dissimilarity in mean achievement test scores in quantity economics for the students' exposed to DQEST with feedback and remediation, DQEST with feedback, DQEST only and non DQEST was significant $(\mathrm{F}(3,209)=$ 22.3114, p-value $<0.05)$. Bonferroni's Post Hoc analysis carried out to determine where the significance lies revealed that the treatment condition that was significantly effective in improving students' achievement in quantitative economic was only DQEST with feedback and remediation, while DQEST with feedback, DQEST only and non-DQEST treatments in this study were not significantly effective in improving students' achievement. That is, between the four experimental groups, significant difference was gotten in favor of the diagnostic test with feedback and remediation group only.

The findings of this study implies that regular testing is more effective in improving achievement when accompanied with feedback and remediation. This study outcome is in line with the results of previous authors which remarked that continuous testing only could not produce sufficient inducement for mathematics and physics learning correspondingly (Ajogbeje (2011); Ajogbeje \& Alonge (2012); Erinosho (1988); Fatoke, Ogunlade \& Ibidiran (2013); Ofem, Idika \& Ovat (2017). They also observed that greater intellectual achievement was obtained from learners who undergo remediation than those undertaking instructions with no remediation. The feedback plus remediation treatment must have been of help to the students who benefited from it. Thus, constant testing with no feedback and remediation seen in the schools might be instrumental in poor students' achievement in examinations as well as learning constraint (Hamsi, 2012).

The non-statistical significant dissimilarity among the mean scores in TAQE of diagnostic test with feedback group and diagnostic test only group, diagnostic test with feedback and non-diagnostic test group, diagnostic test only and non-diagnostic test groups as seen in this study was unexpected. This is because frequent testing along with feedback or frequent testing alone according to Hamisi (2012) study would be expected to provide enough stimulus and motivation for an increased achievement in quantitative economics. Nevertheless, this result is in agreement with that conducted in Ibadan, Nigeria by Erinosho in 1988. Who supported that diagnostic test with feedback condition exert higher significant impact than when only diagnostic test was provided. It also corroborates Crisp's (2007) conclusion that providing feedback only may not result in upgrading the student performance in a following attempt even for a similar subject.

On the other hand, the non-statistical significant outcome contrasted with the findings of Betts et al, (2015) and Ajogbeje and Alonge, (2012). Their findings revealed that testing steered a significant real result. When tested daily than weekly or within three weeks intermissions, students were able to establish added regular study habits. These non-significant results could be attributed to the non-use of DQEST/TAQE scores/grades to classify as well as create a public record of schools and students' academic achievement that can accurately and effectively communicate to others their level of mastery of quantitative economics.

According to Allen (2005), grades indicating students' academic achievement in a subject motivates learners to learn and to enhance their achievement. It helps educators establish a learning environment that is student-centered, stimulates students to be self-regulated learners and encourages self-evaluation. However, this study findings tends to support how relevant remediation is in the evaluation process. It further proposes that consistent testing only is non-significant in enhancing quantitative economics achievement. Thus the tendency of incessant testing with no feedback and remediation seen in our secondary schools might be influential in constraining rather than stimulating learning.

Results of this study further reveals that male and female students mean scores in quantitative economics from pretest to posttest generally increased. Although there were observed mean differences in favor of the female students, there exist non-significant dissimilarity between males and females student achievement in TAQE.

A study by Ajogbeje in 2011 revealed that differences in mean achievement for male and female students in quantitative subjects had no significant impact. His findings are supported by this study results since we found no significant dissimilarity between males and females student posttest mean achievement marks. Also, no significant gender dissimilarities in the achievement of college students in mathematics- a quantitative subject- was recorded by Adigun et al., (2015). Nevertheless, the result is in disparity with that of Campbell and Beaudry in 1998, U. S. 
Department of Education in 2000, and U. S. Department of Education in 2001 which recorded gender dissimilarities in achievement of quantitative subjects. It then means that, in this study, the differences observed in the males and females' student mean scores in TAQE was not significant. Together, male and female students benefited equally from the treatments.

\section{Conclusion}

In view of the findings of this study, the researchers conclude that once diagnostic tests are used for the purpose of diagnoses, the results obtained are often higher than when provided as a series of summative tests. This occurred in this study when the results of DQEST helped in finding out the students' weak learning points in quantitative economics and the necessary remediation or corrections given. Therefore, mean achievement scores in TAQE for students provided with DQEST with feedback and remediation treatment was significant when compared with those treated with either DQEST with feedback, DQEST only or non DQEST. This study findings further revealed that gender of students exercise non-significant effect on intellectual achievement in quantitative economics among secondary school students.

\section{Recommendations}

Taking into cognizance the findings of this study and the conclusions made, the researchers recommends the following:

1. Students should seek for and utilize diagnostic tests coupled with feedback and remediation available to them in preparation for both internal and external examinations.

2. Economics teachers need to help their students have a positive view towards quantitative economics by exposing their learners with consistent diagnostic testing, feedback and an adequate corrective measure-remediation.

3. School heads/school administrators ought to permit and offer inducements for their teachers so as to attend conferences, workshops, seminars and trainings that will improve their performances. As such they can obtain essential expertise for developing diagnostic tests; how to merge diagnostic evaluation with classroom instruction.

4. The researcher finally recommends a further study on the use of DQEST with feedback and remediation by future researchers.

\section{Strengths and Limitations}

In the course of the study, some strengths and limitations were encountered. Perhaps, this work is the first investigation in Nigeria checking the effect of diagnostic testing on students' academic achievement in secondary school quantitative economics. However, some students were reluctant to participate in the experiment or answer the DQEST/TAQE items on the ground that the test results would not be used for promotion or to award certificates. Some items might perhaps be hastily answered and options chosen by guessing.

\section{References}

Ajogbeje, O. J. (2011). Effect of formative testing on students' achievement in junior secondary school mathematics. European Scientific Journal, 8(8), 1857-7881.

Ajogbeje, O. J., \& Alonge, M. F. (2012). Effect of feedback and remediation on students' achievement in junior secondary school mathematics. International Education Studies, 5(5), 153-162. https://doi.org/10.5539/ies.v5n5p153

Adigun, J., Onihunwa, J., Irunokhai, E., Sada, Y., \& Adesina, O. (2015). Effect of gender on students' academic performance in computer studies in secondary schools in new Bussa, Borgu Local Government of Niger State. Journal of Education and Practice, 6(33), 1-7.

Alderson, J. C. (2005). Diagnosing foreign language proficiency: The interface between learning and assessment. London: Continuum.

Allen, J. D. (2005). Grades as valid measures of academic achievement of classroom learning. The Clearing House: A Journal of Educational Strategies, Issues and Ideas, 78(5), 218-223. 
https://doi.org/10.3200/TCHS.78.5.218-223

Betts, J. R., Hahn, Y., \& Zau, A. C. (2015). Does diagnostic math testing improve student learning? California: $\begin{array}{llll}\text { Public } & \text { Institute } & \text { (PPIC). } & \text { Retrieved from }\end{array}$ https://www.monash.edu/_data/assets/pdf_file/0003/925644/can_testing_improve_student_learning_an_evalua tion_of_the_mathematics_diagnostic_testing_project.pdf

Campbell, J. R., \& Beaudry, J. S. (1998). Gender gap linked to differential socialization for high-achieving senior mathematics students. Journal of Educational Research, 9(1), $140-148$. http://dx.doi.org/10.1080/00220679809597534

Casmir N. E. (2014). Formative tests as a predictor of students' performance in diagnostic tests in secondary school Biology. Journal of Education and Practice, 5(29), 12-26.

Crisp, B. R. (2007). Is it worth the effort? How feedback influences students' subsequent sub-mission of assessable work. Assessment and Evaluation in Higher Education, 32(5), 571-81.

Dixon, J. J. (2009). The diagnostic prescriptive assessment. Retrieved from http://www.eddps.com/dpa.html

Eleje, L. I., \& Esomonu, N. P. M. (2018). Test of achievement in quantitative economics for secondary schools: Construction and validation using item response theory. Asian Journal of Education and Training, 4(1), 18-28. https://doi.org/10.20448/journal.522.2018.41.18.28

Erinosho, S. Y. (1988). The effect of formative evaluation on the performance of students in Physics (Unpublished dissertation). University of Ibadan, Ibadan.

Esomonu, N. P. M., \& Eleje, L. I. (2017). Diagnostic quantitative economics skill test for secondary schools: Development and validation using item response theory. Journal of Education and Practice, 8(22), 110-125. Retrieved from www.iisteorg

Evaluation and enrichment in teaching mathematics. (n.d). Diagnostic testing and remedial teaching in mathematics. Retrieved from www.egyankosh.ac.in/bitstream/123456789/7821/1/Unit-9.pdf

Fatoke, A. O., Ogunlade, T. O., \& Ibidiran, V. O. (2013). The effects of problem-solving instructional strategy and numerical ability on students' learning outcomes. The International Journal of Engineering and Science (IJES), 2(10), 97-102.

Hamisi, S. K. (2012). Effects of frequent assessment on achievement and attitude in mathematics in Kenya a case study of Migori district. Retrieved from http://erepository.uonbi.ac.ke/bitstream/handle/11295/74333/HAMISI_Effects

Highland Council of Education, Culture and Sport Services. (2010). Diagnostic assessment. Retrieved from www.keyskillssupport.net/teaching/assessment/

Jang, E. E. (2009). Cognitive diagnostic assessment of L2 reading comprehension ability: Validity arguments for Fushion model application of language assessment. Language Testing, 2(6), 31-73. https://doi.org/10.1177/0265532208097336

Ketterlin-Geller, R., \& Yovanoff, P. (2009). Diagnostic assessment in mathematics to support instructional decision making. Practical Assessment, Research and Evaluation, 14(16), 2.

Ofem, U. J., Idika, D. O., \& Ovat, S. V. (2017). Effect of Diagnostic and Feedback Assessment Approaches in Enhancing Achievement in Mathematics among Secondary School Students in Calabar Municipality. International Journal of Scientific Research in Education, 10(2), 221-227.

Ozan, C., \& Kincal, R. Y. (2018). The effects of formative assessment on academic achievement, attitudes toward the lesson, and self-regulation skills. Educational Sciences: Theory \& Practice, 18, 85-118. http://dx.doi.org/10.12738/estp.2018.1.0216

Richards, B. J. (2008). Formative assessment in teacher education: The development of a diagnostic language test for trainee teachers of German. British Journal of Educational Studies, 56(2), 184-204. https://doi.org/10.1111/j.1467-8527.00403.x

Rusrus, H. R. (2007). A suggested program to remedy the common mistakes in solving the mathematical problems for the eleventh literary section graders in Gaza. Retrieved from http://library.iugaza.edu.ps/thesis/95917.pdf

Schaffer, D. L. (2013). The development and validation of a three-tier diagnostic test measuring pre-service elementary education and secondary science teachers' understanding of the water cycle. Retrieved from 
https://mospace.umsystem.edu/xmlui/bitstream/handle/10355/37809/research.pdf?...

Shavelson, R. J., Yin, Y., Furtak, E. M., Ruiz-Primo, M. A., Ayala, C. C., Young, D. B., \& Pottenger, F. M. (2008). On the role and impact of formative assessment on science inquiry teaching and learning. In J. Coffey, R. Douglas, \& C. Stearns (Eds.), Assessing science learning: Perspectives from research and practice (pp. 21-36). Arlington, VA: National Science Teachers Association Press.

U. S. Department of Education. (2000). The condition of education 2000 (NCES 2000-062). Washington, DC: National Center for Education Statistics, Office of Educational Research and Improvement. Retrieved from https://nces.ed.gov/pubs2000/2000062.pdf

U. S. Department of Education. (2001). The nation's report card: Mathematics highlights 2000 (NCES 2001-518). Washington, DC: National Center for Education Statistics, Office of Educational Research and Improvement. Retrieved from https://nces.ed.gov/nationsreportcard/pubs/main2000/2001518.aspx

WAEC. Economics paper 2- the West African Examinations Council. (2012, 2014, 2017, 2018). Retrieved from https://waeconline.org.ng/e-learning/Economics/econsmain.html 